\title{
Subdivision or Multiplication? The Choice of Calibration Design for Multiples of Kilogram
}

\author{
Adriana Vâlcu, Dragoş Boiciuc \\ National Institute of Metrology, Şos. Vitan Bârzeşti nr. 11, sect. 4, 042122 Bucharest, Romania \\ Email: adriana.valcu@inm.ro; dragos.boiciuc@inm.ro;
}

\begin{abstract}
The realization, maintenance and dissemination of the SI base unit, the kilogram, is one of the tasks of the NMI's mass laboratory and is assured by means of reference standards which are traceable to the International Kilogram Prototype through the mass of the National Prototypes. This paper describes the dissemination of mass scale from $1 \mathrm{~kg}$ reference standard to weights of $E_{1}$ class between $(1 . .10) \mathrm{kg}$, using one of the two methods of calibration: subdivision or multiplication. The paper compares the variance of each weight obtained by both methods. The presented subdivision method deals with a link of standards following the example of Mihailov Romanowski where the measurements start downwards from $10 \mathrm{~kg}$ to $1 \mathrm{~kg}$. The multiplication method is the one usually used in many calibration laboratories and starts from $1 \mathrm{~kg}$ to $10 \mathrm{~kg}$. The paper also presents an example of calibration and uncertainty calculations.
\end{abstract}

Keywords: mass, kilogram prototype, calibration, measurements

\section{INTRODUCTION}

G ENERALLY, the objective in the search for better designs is to obtain a minimum value of variance (if the weights are used independently from each other) or covariance (if the weights are used in combination). This can be achieved through an increased number of weighings by addition and repetition of elementary measurements. A set of $(10 \ldots 1) \mathrm{kg}$ has usually the following composition: $10 \mathrm{~kg}, 5 \mathrm{~kg}, 2 \mathrm{~kg}, 2^{*} \mathrm{~kg}, 1 \mathrm{~kg}$

The weighing is performed always as substitution weighing. This means that single weights or combinations of weights are always compared with another combination of the same nominal value.

The difference $\Delta \mathrm{m}$ (corrected for the buoyancy effect) is the difference of balance readings calculated from one weighing cycle (RTTR) to eliminate possible linear drifts of the balance readings.

Note that $\mathrm{y}=$ the new mass difference corrected

$$
\mathrm{y}=\Delta \mathrm{m}+\left(\rho_{\mathrm{a}}-\rho_{\mathrm{o}}\right)\left(V_{\mathrm{j}}-V_{\mathrm{r}}\right)
$$

$\rho_{0}=1.2 \mathrm{~kg} \cdot \mathrm{m}^{-3}$ the reference air density;

$\rho_{\mathrm{a}}=$ air density at the time of the weighing and

$V_{\mathrm{j}}, V_{\mathrm{r}}$ are the volumes of the standards (or the total volume of each group of weights) involved in the measurement. For all the measurements only one mass comparator is used so as to have observations of the same accuracy.

\section{CALIBRATION METHODS}

\section{Subdivision method}

In the calibration of multiples of the unit of mass, with a link of standards following the example of Mihailov Romanowski, the principle used is as follows: "The ratio which exists between the highest mass of the set and the standard (unit) is utilized to circumvent the condition which states that the orthogonality of a system can be realized only if the highest mass is the defining standard" $[1,2]$.

For set of $(10 \ldots 1) \mathrm{kg}$ it is extended number of weighings. A fully automated mass comparator is available to obtain a minimum value of the diagonal elements in the inversion of matrices. The system of equations is given below:

$$
\begin{aligned}
& (10)=\mathrm{M} \\
& -(10)+(5)+(2)+\left(2^{*}\right)+(1) \quad=y_{1} \\
& -(10)+(5)+(2)+\left(2^{*}\right)+(1 *) \quad=\mathrm{y}_{2} \\
& (5)-(2)-\left(2^{*}\right)-(1) \quad=y_{3} \\
& \text { (5) - (2) - }\left(2^{*}\right)-\left(1^{*}\right) \quad=\mathrm{y}_{4} \\
& (2)-(2 *)+(1)-(1 *) \quad=\mathrm{y}_{5}, \mathrm{y}_{6} \\
& (2)-(2 *)-(1)+(1 *) \quad=\mathrm{y}_{7}, \mathrm{y}_{8} \\
& \text { (2) - } \quad(1)-\left(1^{*}\right) \quad=\mathrm{y}_{9}, \mathrm{y}_{10} \\
& \left(2^{*}\right)-\quad(1)-\left(1^{*}\right)=\mathrm{y}_{11}, \mathrm{y}_{12}
\end{aligned}
$$

Note: $\mathrm{X}=\left(\mathrm{x}_{\mathrm{ij}}\right)$ the design matrix with $\mathrm{i}=1 \ldots \mathrm{n} ; \mathrm{j}=1 \ldots \mathrm{k} ; \mathrm{x}_{\mathrm{ij}}=$ $1,-1$ or 0

$\beta$ is $\left(\beta_{\mathrm{j}}\right)$ vector of unknown departures and

$Y$ is $\left(y_{\mathrm{i}}\right)$ vector of measured values (including buoyancy corrections as is shown in eq. 1)

If $\left(\mathrm{X}^{\mathrm{T}} \cdot \mathrm{X}\right)$ is the matrix of the normal equations then

$$
\left(X^{\mathrm{T}} \cdot \mathrm{X}\right) \cdot \beta=\mathrm{X}^{\mathrm{T}} \cdot \mathrm{Y}
$$

where $\mathrm{X}^{\mathrm{T}}$ is transpose of $\mathrm{X}$. 


$$
X=\left|\begin{array}{ccccc}
(5) & (2) & \left(2^{*}\right) & (1) & (1)^{*} \\
1 & 1 & 1 & 1 & 0 \\
1 & 1 & 1 & 0 & 1 \\
1 & -1 & -1 & -1 & 0 \\
1 & -1 & -1 & 0 & -1 \\
0 & 1 & -1 & 1 & -1 \\
0 & 1 & -1 & 1 & -1 \\
0 & 1 & -1 & -1 & 1 \\
0 & 1 & -1 & -1 & 1 \\
0 & 1 & 0 & -1 & -1 \\
0 & 1 & 0 & -1 & -1 \\
0 & 0 & 1 & -1 & -1 \\
0 & 0 & 1 & -1 & -1
\end{array}\right| \quad Y=\left|\begin{array}{c}
y_{1}+10 r \\
y_{2}+10 r \\
y_{3} \\
y_{4} \\
y_{5} \\
y_{6} \\
y_{7} \\
y_{8} \\
y_{9} \\
y_{10} \\
y_{11} \\
y_{12}
\end{array}\right| \beta=\left|\begin{array}{c}
\beta_{1} \\
\beta_{2} \\
\beta_{3} \\
\beta_{4} \\
\beta_{5} \\
\beta_{6}
\end{array}\right|
$$

Starting from " $\mathrm{y}_{5}$ " the measurements were repeated two times.

To convert the natural system into an orthogonal one, the following statement was taken into account: "an orthogonal system of equation of condition can be formed only if the defining weight that is included into the system has the largest mass" [2].

For this reason, the preliminary equation of definition (10) $=\mathrm{M}$ has been introduced into the system of equations. In calibration of multiples, the role of " $\mathrm{M}$ " is assigned to different mass: for the largest mass and for the lowest one [2]. It is assumed that the mass of (10) weight defines a temporary mass unit " $r$ ", where $(10)=\mathrm{M}=10 \mathrm{r}$ and the other weights are expressed [2]. From the system of normal equations the next normal equation in (1) $\mathrm{kg}$ is used:

$$
10(1)=10 \mathrm{r}+\mathrm{N}_{1}
$$

$\mathrm{N}_{1}$ represents the sum of measured values in which the $1 \mathrm{~kg}$ reference (1) is involved and has the form:

$$
\mathrm{N}_{1}=\mathrm{y}_{1}-\mathrm{y}_{3}+\mathrm{y}_{5}+\mathrm{y}_{6}-\mathrm{y}_{7}-\mathrm{y}_{8}-\mathrm{y}_{9}-\mathrm{y}_{10}-\mathrm{y}_{11}-\mathrm{y}_{12}
$$

The value of (1) $\mathrm{kg}$ reference standard is known from previous calibration; its value is introduced in eq.5. Further, " $\mathrm{r}$ " and weight $(10)=10 \mathrm{r}$ can be computed. The value of (10) $\mathrm{kg}$ is used to start the calculation of the other weights. The least squares solutions take the well-known form:

$$
\langle\beta\rangle=\left(X^{T} \cdot X\right)^{-1} \cdot X^{T} \cdot Y
$$

$\left(\mathrm{X}^{\mathrm{T}} \cdot \mathrm{X}\right)^{-1}$ is termed the inverse of $\left(\mathrm{X}^{\mathrm{T}} \cdot \mathrm{X}\right)$ and has the next form:

$$
\left(X^{T} \cdot X\right)^{-1}=\left|\begin{array}{ccccc}
0.25 & 0 & 0 & 0 & 0 \\
0 & 0.1 & 0 & 0 & 0 \\
0 & 0 & 0.1 & 0 & 0 \\
0 & 0 & 0 & 0.1 & 0 \\
0 & 0 & 0 & 0 & 0.1
\end{array}\right|
$$

\section{Analysis of variances for subdivision method}

Taking into account that the weight "10r" has been used as the "temporary" standard, the mass of which is known in terms of (1), it is necessary to propagate the uncertainty of "10r" to the remaining weights. From eq. (5) results [1]:

$$
\operatorname{var} r=\operatorname{var}(1)+\left(\frac{1}{10}\right)^{2} \cdot \operatorname{var} N_{1}
$$

Where var $N_{1}=10 \cdot \mathrm{s}^{2}$ ("s" being calculated according to eq.(15)).

The formula for var (10) is therefore

$$
\operatorname{var}(10)=10^{2} \operatorname{var} r
$$

Having the variance of " $r$ ", from the normal equations, one may calculate the remaining variances for the other weights. For example:

$\operatorname{var}(5)=25 \cdot \operatorname{var} \mathrm{r}+(1 / 4)^{2} \cdot \operatorname{var} N_{5}=25 \cdot \operatorname{var} \mathrm{r}+0.25 \cdot \mathrm{s}^{2}$ with $\operatorname{var} N_{5}=4 \cdot \mathrm{s}^{2}$

$\operatorname{var}(2)=4 \operatorname{var} r+(1 / 10)^{2} \cdot \operatorname{var} \mathrm{N}_{2}=4 \operatorname{var} \mathrm{r}+0.1 \cdot \mathrm{s}^{2}$ with $\operatorname{var} \mathrm{N}_{2}=10 \cdot \mathrm{s}^{2}$

$\operatorname{var}\left(1^{*}\right)=\operatorname{var} \mathrm{r}+(1 / 10)^{2} \cdot \operatorname{var} \mathrm{N}_{1}=\operatorname{var} \mathrm{r}+0.1 \cdot \mathrm{s}^{2}$ with $\operatorname{var} \mathrm{N}^{*}{ }_{1}=10 \cdot \mathrm{s}^{2}$

\section{Multiplication method}

The system of equations contains the same measurements combination of weights as is shown in the subdivision method, the difference being that the measurements start from the smallest mass up to the largest one [3]. The value of (1) $\mathrm{kg}$ reference standard is known from previous calibration.

" $X$ ", $\beta$ and $Y$ have the same signification as is shown above. 


$$
X=\left|\begin{array}{cccccc}
-1 & -1 & 1 & 0 & 0 & 0 \\
-1 & -1 & 1 & 0 & 0 & 0 \\
-1 & -1 & 0 & -1 & 0 & 0 \\
-1 & -1 & 0 & -1 & 0 & 0 \\
1 & -1 & 1 & -1 & 0 & 0 \\
1 & -1 & 1 & -1 & 0 & 0 \\
-1 & 1 & 1 & -1 & 0 & 0 \\
-1 & 1 & 1 & -1 & 0 & 0 \\
-1 & 0 & -1 & -1 & 1 & 0 \\
0 & -1 & -1 & -1 & 1 & 0 \\
-1 & 0 & -1 & -1 & -1 & 1 \\
0 & -1 & -1 & -1 & -1 & 1
\end{array}\right| \quad Y=\left|\begin{array}{l}
y_{1} \\
y_{2} \\
y_{3} \\
y_{4} \\
y_{5} \\
y_{6} \\
y_{7} \\
y_{8} \\
y_{9} \\
y_{10}
\end{array}\right| \quad \beta=\left|\begin{array}{l}
\beta_{1} \\
\beta_{2} \\
\beta_{3} \\
\beta_{4} \\
\beta_{5} \\
\beta_{6}
\end{array}\right|
$$

The least squares solutions are calculated as is shown in eqn. 7. The inverse of $\left(\mathrm{X}^{\mathrm{T}} \cdot \mathrm{X}\right)$ has the next form:

$$
\left(X^{T} \cdot X\right)^{-1}=\left|\begin{array}{ccccccc}
0 & 0 & 0 & 0 & 0 & 0 & 1 \\
0 & 0.20 & 0.20 & 0.20 & 0.50 & 1.00 & 1 \\
0 & 0.20 & 0.5 & 0.40 & 1.00 & 2.00 & 2 \\
0 & 0.20 & 0.40 & 0.50 & 1.00 & 2.00 & 2 \\
0 & 0.50 & 1.00 & 1.00 & 2.75 & 5.00 & 5 \\
0 & 1.00 & 2.00 & 2.00 & 5.00 & 10.00 & 10 \\
1 & 1 & 2 & 2 & 5 & 10 & 0
\end{array}\right|
$$

The last column and row contains the factor $h_{\mathrm{j}}=m_{\beta \mathrm{j}} / m_{\mathrm{r}}$, the ratios between the nominal values of the unknown weights $\left(m_{\beta \mathrm{j}}\right)$ and one of the reference $\left(m_{\mathrm{r}}\right)$.

\section{Analysis of variances for multiplication method}

If the adjusted mass difference of the weighing equations is $\langle Y\rangle=X \cdot\langle\beta\rangle$ the residual for each equation is calculated as follows:

$$
\langle e\rangle=\operatorname{res}_{i}=Y-\langle Y\rangle
$$

The standard deviation "s" of the observations is calculated by:

$$
s=\sqrt{\frac{1}{v} \sum_{i=1}^{n} r^{2} s_{i}^{2}}
$$

The residuals "res." are the elements of the vector $\langle e\rangle$; " $v$ " = $\mathrm{n}-\mathrm{k}$ represents the degrees of freedom (" $\mathrm{n}-\mathrm{k}$ " is the difference between the number of performed observations and the number of the unknown).

The variance - covariance matrix for $\langle\beta\rangle$ is given by

$$
V_{\beta}=\mathrm{s}^{2}\left(\mathrm{X}^{\mathrm{T}} \cdot \mathrm{X}\right)^{-1}
$$

The diagonal elements of $V_{\beta}$ are the variances on the values of the solutions $\langle\beta\rangle$.The off-diagonal elements of the matrix give the covariance between the weights. The uncertainty of type A for a particular weight is given by: $u_{A(B j)}=s \sqrt{c_{i j}}$, where the diagonal elements of the matrix $\left(\mathrm{X}^{\mathrm{T}} \cdot \mathrm{X}\right)^{-1}$ are denoted $c_{\mathrm{ij}}$. The complete variance of a particular unknown weight will be:

$$
\operatorname{var}_{(\beta \mathrm{j})}=\mathrm{s}^{2} \cdot c_{\mathrm{ij}}+h_{\mathrm{j}}^{2} \cdot u_{\mathrm{mr}}^{2}
$$

\section{PRACTICAL EXAMPLE}

Equipment: A comparator CC10000 U-L - Sartorius was used for all comparisons and consequently the observations are of the same accuracy. Comparison weighing was carried out completely automatically and measurement data were gathered, evaluated and recorded.

A precise "climate station" system YCM02C was used for an accurate determination of air density. This system consists of a data collection unit with a built-in power supply, a precision sensor for barometric pressure, an electrical aspiration psychrometer, and data evaluation software for installation in a PC. Technical requirements for YCM02C are:

Temperature: measuring range: $(0 \ldots 40)^{\circ}$

$$
\text { Readability: } 0.01 \mathrm{~K} \quad \mathrm{U}(\mathrm{k}=2): 0.1 \mathrm{~K}
$$

Relative humidity: Measuring range: $(0 \ldots 100) \%$

$$
\text { Resolution : } 0.1 \% \quad \mathrm{U}(\mathrm{k}=2): 1.0 \%
$$

Barometric pressure: Measuring range: $(35 \ldots 1310) \mathrm{hPa}$

$$
\text { Readability : } 0.1 \mathrm{hPa} \quad \mathrm{U}(\mathrm{k}=2) \quad: 0.25 \mathrm{hPa}
$$

From the air parameters, the air density is calculated using the equation recommended by the CIPM.

Standards and results: For the calibration, as the known mass is used $1 \mathrm{~kg}$ reference standard having the value determined by a direct comparison against the National Prototype No 2.

The result of this comparison (conventional mass) was: $m_{\mathrm{r}}=0.999999974 \mathrm{~kg} \quad$ with $U\left(\mathrm{~m}_{\mathrm{r}}\right)=0.048 \mathrm{mg}(\mathrm{k}=2)$. The observed mass differences $Y$ (with buoyancy corrections) are given below. The vector $\langle\beta\rangle$ with the unknown masses, calculated according to equations (7) described above, gives the same results for both methods:

\section{For subdivision method}

$$
Y=\left|\begin{array}{c}
-2.6279 \\
-2.6021 \\
0.6119 \\
0.5745 \\
-0.0708 \\
-0.0818 \\
0.0029 \\
0.0099 \\
0.5841 \\
0.6033 \\
0.6194 \\
0.6347
\end{array}\right| \quad\langle\beta\rangle=\left|\begin{array}{c}
10 \mathrm{~kg}+5.59 \mathrm{mg} \\
5 \mathrm{~kg}+1.78 \mathrm{mg} \\
2 \mathrm{~kg}+0.58 \mathrm{mg} \\
2 * k g+0.61 \mathrm{mg} \\
1 \mathrm{~kg}-0.026 \mathrm{mg} \\
1 * k g+0.01 \mathrm{mg}
\end{array}\right|
$$




\section{For multiplication method}

$$
Y=\left|\begin{array}{c}
0.5841 \\
0.6033 \\
0.6194 \\
0.6347 \\
-0.0708 \\
-0.0818 \\
0.0029 \\
0.0099 \\
0.6119 \\
0.5745 \\
2.6279 \\
2.6021
\end{array}\right| \quad\langle\beta\rangle=\left|\begin{array}{c}
1 k \mathrm{~kg}-0.026 \mathrm{mg} \\
2 \mathrm{~kg}+0.58 \mathrm{mg} \\
2 * k g+0.61 \mathrm{mg} \\
5 \mathrm{~kg}+1.78 \mathrm{mg} \\
10 \mathrm{~kg}+5.59 \mathrm{mg}
\end{array}\right|
$$

\section{Analysis of variances}

From the residual res $_{\mathrm{i}}$ calculated for each method according to eq (14), the same standard deviation for both methods is obtained: $s=0.00010 \mathrm{mg}$

The variance calculated for each weight according to equations (11) and equation (17) gives the next results:

\section{For subdivision method}

For multiplication method

$\operatorname{var}_{(\beta j)}=\left|\begin{array}{c}10 \mathrm{~kg}: 0.059 \\ 5 \mathrm{~kg}: 0.015 \\ 2 \mathrm{~kg}: 0.002 \\ 2 * \mathrm{~kg}: 0.002 \\ 1 * k g: 0.0006\end{array}\right| \mathrm{mg}$

$$
\operatorname{var}_{(\beta j)}=\left|\begin{array}{c}
1 \mathrm{~kg}: 0.0006 \\
2 \mathrm{~kg}: 0.002 \\
2 * \mathrm{~kg}: 0.002 \\
5 \mathrm{~kg}: 0.015 \\
10 \mathrm{~kg}: 0.059
\end{array}\right|
$$

\section{CONCLUSION}

Two calibration schemes for $\mathrm{E}_{1}$ weights between $(1 \ldots 10)$ $\mathrm{kg}$ were described, while two methods of calibration were used: subdivision or multiplication, in terms of a $1 \mathrm{~kg}$ reference standard.

The conventional mass and variances obtained from both methods are equal, only the type A uncertainty is slightly different.

The advantage of the former is the orthogonality of the scheme (orthogonality is advantageous only when all the weighings in the design have the same variance [4]).

An orthogonal design could reduce variances (if the weights are used independently) and covariances (if the weights are used in combination). In this way, covariances will be of importance if the uncertainties of combinations of weights are required. The subdivision method described for (10...1) $\mathrm{kg}$ can be also applied to other series of weights ( for example from $100 \mathrm{~g}$ to $10 \mathrm{~g}$ or $10 \mathrm{~g}$ to $1 \mathrm{~g}$ ) used in practical metrology. Taking into account that both methods lead to the same final results, we should take the easiest way.

\section{REFERENCES}

[1] Romanowski, M. Basic Theory of the calibration of mass standards. Unpublished.

[2] Mihailov, G., Romanowski, M. (1990). Calibration of the multiples, of the unit of mass. Metrologia 27, 17-18.

[3] Vâlcu, A. (1996). Greutati etalon cl. E1. NML 3-06-95, editia oficiala (pp. 20-21).

[4] Morris, E.C. (1993). Decade design for weighings of Non-uniform Variance. Metrologia 29, 373-377. 